\title{
Bile duct obstruction after transjugular intrahepatic portosystemic shunt implantation
}

Transjugular intrahepatic portosystemic shunt (TIPS) implantation is a standard treatment option for patients with liver cirrhosis and the complications of portal hypertension [1]. The safety and efficacy of the procedure have been studied extensively [2]. Biliary complications are rare and comprise biliary fistula and bilioma $[3,4]$.

A 50-year-old woman with alcoholic liver cirrhosis was admitted with progressive jaundice. She had received a TIPS (Viatorr, $8 \mathrm{~cm}$; Gore, Newark, Delaware, USA) 18 months earlier for refractory ascites but rectangular stent entry in the portal vein had caused poor TIPS flow. Therefore, 8 months after the primary procedure, an overlapping stent $(20 \mathrm{~mm}$ extension) had been placed because of recurrent ascites. Thereafter, the hepatic venous pressure gradient decreased from $24 \mathrm{mmHg}$ to $7 \mathrm{mmHg}$.

On admission, her liver function tests results were all elevated: total bilirubin $483.7 \mu \mathrm{mol} / \mathrm{L}$, alkaline phosphatase $3.85 \mu \mathrm{kat} / \mathrm{L}$, gamma glutamyl transferase $2.40 \mu \mathrm{kat} / \mathrm{L}$, aspartate aminotransferase $1.82 \mu \mathrm{kat} / \mathrm{L}$, and alanine aminotransferase $2.83 \mu \mathrm{kat} / \mathrm{L}$. An ultrasound scan showed dilated bile ducts in the right hepatic lobe distal to the portal TIPS entry point ( Fig. 1). The patient underwent endoscopic retrograde cholangiography, which revealed a severe obstruction to a branch of the right hepatic bile duct without intraductal blockage ( Fig.2). A computed tomography (CT) scan confirmed bile duct compression by the TIPS extension ( Fig.3).

The patient was evaluated for liver transplantation. However, because of a relapse of her alcohol abuse, she was regarded as not suitable for transplantation. Although cholestasis persisted in the affected liver segments, biliary drainage was not performed to avoid the potential development of a portobiliary fistula in the compressed bile duct. Biliary stent implantation requires regular follow-up care, which could not be ensured in this noncompliant patient.

This case highlights the risk of mechanical cholestasis as a potential complication of TIPS. As such, jaundice following TIPS im-
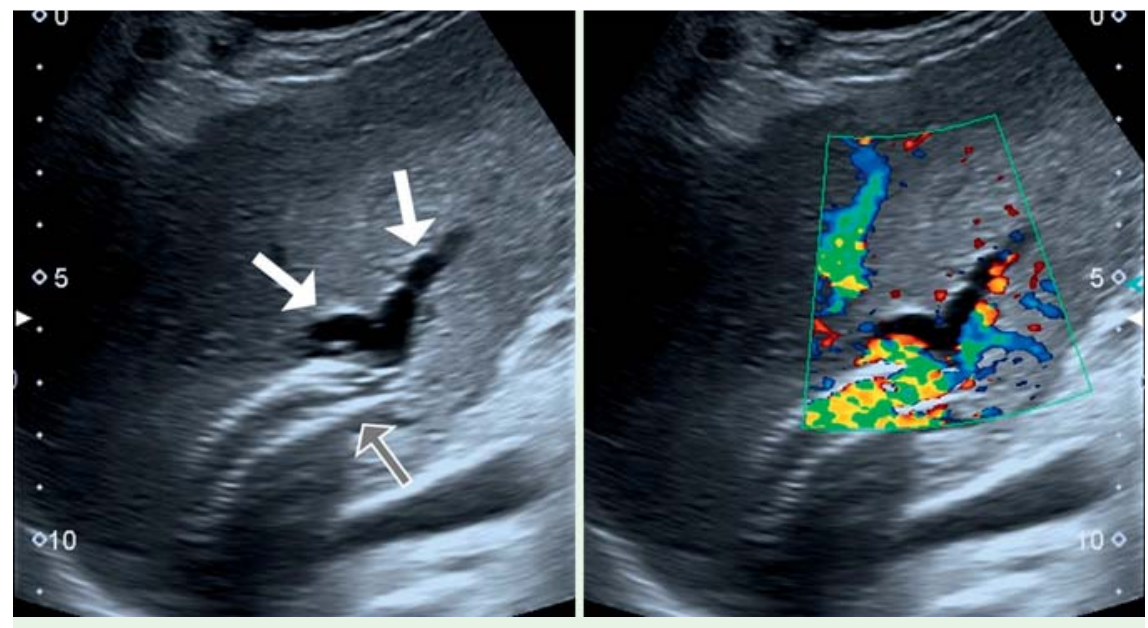

Fig. 1 Abdominal ultrasound (transcostal view) in a 50-year-old woman with alcoholic liver cirrhosis showing dilated bile ducts (white arrows) in the right hepatic lobe. The site of the biliary obstruction is situated next to the end of the portal transjugular intrahepatic portosystemic shunt (grey arrow).

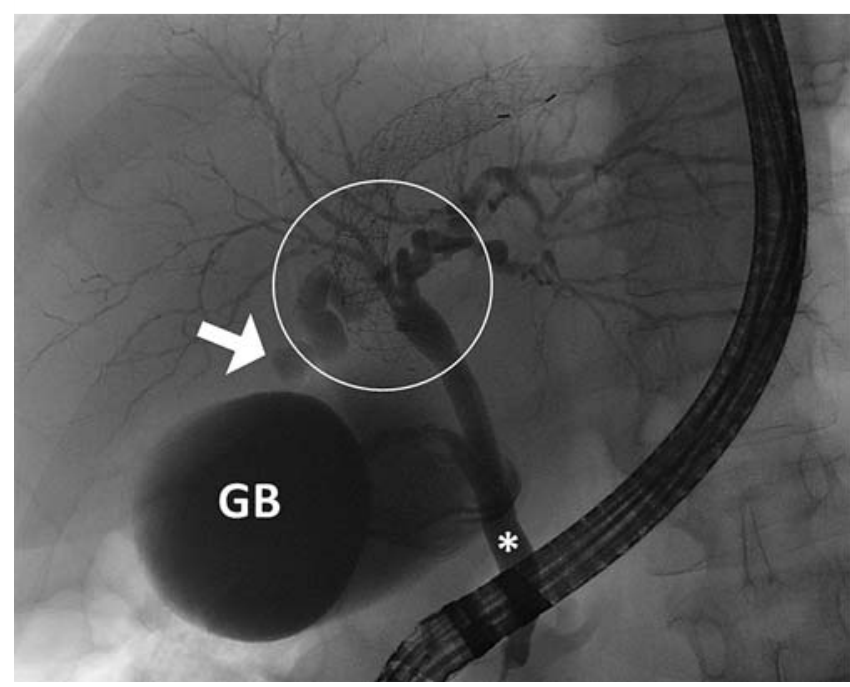

Fig. 2 Image during endoscopic retrograde cholangiography showing an obstruction of a branch of the right hepatic bile duct (white arrow) that was being caused by external compression at the crossing point of the transjugular intrahepatic portosystemic shunt (circle). $\mathrm{GB}$, gallbladder; ${ }^{*}$ common bile duct.

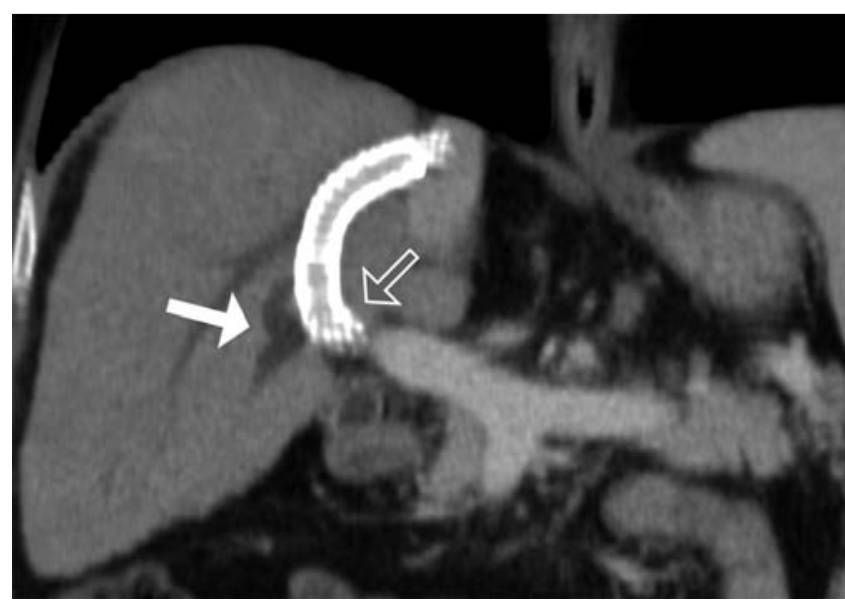

Fig. 3 Multiplanar reconstruction of the computed tomography (CT) scan showing compression of a bile duct in the right lobe of the liver (white arrow) by the end extension of the portal transjugular intrahepatic portosystemic shunt (grey arrow). 
plantation should not be considered to be the result only of deterioration in hepatic function. In most cases ultrasound is the method of choice to exclude biliary obstruction in such patients.

\section{Endoscopy_UCTN_Code_CCL_1AZ_2AI}

\section{Competing interests: None}

\section{T. Karlas ${ }^{1,2}$, A. Hoffmeister ${ }^{2}$, J. Fuchs ${ }^{3}$, M. Tröltzsch ${ }^{2,4}$, V. Keim²,4}

${ }^{1}$ IFB Adiposity Diseases, Leipzig University Medical Center, Leipzig, Germany

2 Department of Internal Medicine, Neurology, and Dermatology, Medical Clinic for Gastroenterology and Rheumatology, University Hospital Leipzig, Leipzig, Germany

3 Department of Diagnostics and Interventional Radiology, University Hospital Leipzig, Leipzig, Germany

${ }^{4}$ Interdisciplinary Ultrasound Unit, University Hospital Leipzig, Leipzig, Germany

\section{Acknowledgment}

This work was supported by the Federal Ministry of Education and Research (BMBF), Germany; FKZ: 01E01001.

\section{References}

1 European Association for the Study of the Liver. EASL clinical practice guidelines on the management of ascites, spontaneous bacterial peritonitis, and hepatorenal syndrome in cirrhosis. J Hepatol 2010; 53: 397-417

2 Pomier-Layrargues G, Bouchard L, Lafortune $M$ et al. The transjugular intrahepatic portosystemic shunt in the treatment of portal hypertension: current status. Int J Hepatol 2012; DOI: $10.1155 / 2012 / 167868$

3 Duller D, Kniepeiss D, Lackner C et al. Biliary obstruction as a complication of transjugular intrahepatic portosystemic shunt. Liver Transpl 2009; 15: 556-557

4 Peynircioglu B, Cho KJ, Cwikiel W. Portal hypertension and obstructive jaundice after hepatic interventions: report of two unusual complications. J Vasc Interv Radiol 2007; 18: 567-571
Bibliography

Dol http://dx.doi.org/

10.1055/s-0032-1325898

Endoscopy 2013; 45: E47-E48

(c) Georg Thieme Verlag KG

Stuttgart · New York

ISSN 0013-726X

\section{Corresponding author}

\section{Keim, MD}

University Hospital Leipzig

Department of Internal Medicine,

Neurology and Dermatology

Medical Clinic for Gastroenterology

and Rheumatology

Liebigstrasse 20

04103 Leipzig

Germany

Fax: +49-341-9712200

volker.keim@medizin.uni-leipzig.de 